\title{
METODOLOGI PENGEMBANGAN MODEL SIMULASI UNTUK EVALUASI KESELAMATAN PENUMPANG FREEFALL LIFEBOAT
}

\author{
Aulia Windyandari \\ Program Diploma III Teknik Perkapalan \\ Fakultas Teknik Universitas Diponegoro
}

\begin{abstract}
Aulia Windyandari, in paper simulation model of development method for passenger savety evaluation of freefaal lifeboat explain that since the launching procedure of Freefall Lifeboat (FFL) may have an impact with the water surface, the occupant injury is possible be occured in the evacuation process of the offshore structures. The FFL shock acceleration has been conducted by the impact force when the lifeboat entry the water surface. If the shock acceleration over the human conciousness allowance, the serious injury will be happened during the FFL launching.

According to the conditions, the IMO regulations have standard for the acceptance criteria of FFL shock acceleration induced by water entry impact load. The results measurement of Combined Acceleration Ratio Index (CAR) or Combined Dynamic Response Ratio Index (CDRR) should be comply with the IMO index criteria.

In this paper, the methodology of FFL acceleration response prediction by the simulation model analysis will be proposed. The simulation model will be developed by using LS-Dyna code. The Simplified Arbitratry Lagrangian Eulerian Coupling will be used to define the coupling analysis between the Lifeboats (Lagrangian elements) with Water Fluids (the Eulerian Elements)
\end{abstract}

Keywords: Free Fall Lifeboat, Response Acceleration, Impact Load

\section{PENDAHULUAN}

Latar Belakang

Meskipun evakuasi yang aman pada sebuah offshore structure dan kapal adalah hal yang sudah lama diangkat sebagai isu utama, namun permasalahan mengenai hal ini masih menjadi perhatian banyak orang, khususnya di kalangan eksplorasi dan produksi bangunan lepas pantai. Ketertarikan di bidang evakuasi ini menjadi lebih kuat setelah adanya realita tentang kecelakaan yang terjadi pada offshore structure, telah mengakibatkan timbulnya korban jiwa. Sebagai contoh adalah Ocean Ranger yaitu sebuah konstruksi semi submersible yang digunakan untuk pengeboran lepas pantaidi wilayah Grand Banks pada akhir tahin 1970 dan awal tahun 1980. Kapal ini tenggelam karena ganasnya kondisi gelombang di tahun 1982, dengan korban meninggal di laut lebih dari 80 awak pekerja. Contoh yang lain, Piper Alpha sebuah fasilitas produksi lepas pantai hilang di Laut Atlantik Utara di tahun 1988. Bencana bangunan lepas pantai ini disebabkan adanya ledakan gas pada struktur platform yang diikuti dengan terjadinya kebakaran besar, hingga menghabisi konstruksi tersebut, Gambar 1. Kasus ini, hampir 200 awak pekerja kehilangan nyawa. Sayangnya hal ini tidak pernah tercatat dan diketahui oleh banyak orang, bahwa peristiwa ini juga telah memakan banyak korban jiwa.

Sarana untuk evakuasi keadaan bahaya tersebut salah satunya adalah Freefall Lifeboat (FFL).
Keunikan dari sarana ini adalah prosedur peluncuran yang menggunakan gravitasi dan gerak jatuh bebas, sehingga terjadi tumbukan (impact) dengan permukaan air. Fenomena tumbukan terhadap permukaan air tersebut memberikan respon kejutan (Shock) dalam bentuk akselerasi yang diterima oleh awak pengguna (Occupant). Bila besar respon akselerasi FFL melebihi batas ambang, cidera serius dapat terjadi pada pengguna FFL. Adanya potensi terjadinya cidera akibat proses peluncuran FFL, maka International Maritime Organization (IMO) mengeluarkan standar kriteria respon FFL akibat tumbukan dengan permukaan air, [1]. Kriteria yang dikeluarkan oleh IMO adalah Combined Acceleration Response (CAR) dan Combined Dynamic Response Ratio (CDRR)

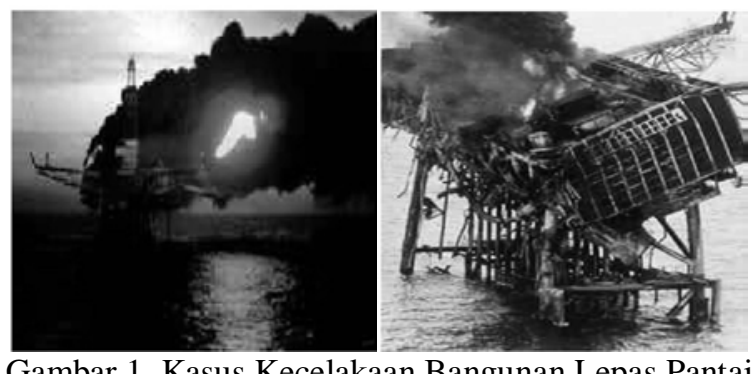

Gambar 1. Kasus Kecelakaan Bangunan Lepas Pantai “The Piper Alpha”

Kita dapat memilih satu diantara 2 kriteria tersebut. Pada kasus ini dipilih CAR (Combined 
Acceleration Respon) karena paling sesuai dengan karakteristik material lifeboat yang dipakai. Kemudian tingkat keselamatan FFL dikaji dengan menghitung Indeks CAR berdasarkan parameter ketinggian lokasi peluncuran FFL, distribusi muatan penumpang FFL, dan sudut Luncur dari rel (Skid) FFL. Bila persyaratan dari IMO tersebut telah dipenuhi, maka FFL dapat diaplikasikan pada bangunan lepas pantai.

Adapun prosedur pengkajian respon akselerasi FFL tersebut dilakukan dengan cara melakukan eksperimen dan pengukuran langsung terhadap model fisik FFL, akibatnya estimasi besarnya respon akselerasi FFL harus dapat dilakukan pada tahap perencanaan, agar produk yang dihasilkan dapat memenuhi kriteria yang ditetapkan oleh IMO. Untuk itu diperlukan sebuah metode untuk memprediksi besarnya respon akselerasi FFL pada proses peluncuran. Dengan adanya metode tersebut diharapkan faktor-faktor yang mempengaruhi besarnya beban tumbukan dapat dilibatkan pada tahapan desain.

\section{Perumusan masalah}

Berdasarkan publikasi sebelumnya pengembangan metode prediksi respon akselerasi FFL akibat beban tumbuk tersebut, dapat dilakukan dengan menggunakan beberapa pendekatan. Pada penelitian ini pendekatan yang digunakan adalah pengembangan model simulasi dengan menggunakan bantuan Software LSTC-LS-Dyna Version 971. Berdasarkan hal tersebut permasalahan dapat dirumuskan sebagai berikut:

- Pemodelan geometri, material dan struktur FFL

- Analisa Kontak (Contact Analysis) antara Rel dengan FFL

- Pemodelan Redaman Dinamik (Dynamic Relaxation) dari Sistem Peluncuran FFL

- Pemodelan fluida air dengan menggunakan elemen euler

- Analisa Lagrangian-Eulerian Coupling (Coupling Analysis) antara air laut dan Lifeboat

Penyelesaian dari beberapa rumusan masalah tersebut dilakukan dengan menggunakan beberapa batasan dan asumsi untuk alasan analisa tertentu, yang meliputi:

- FFL dianggap sebagai rigid body, hal ini diperlukan untuk mempersingkat waktu komputasi

Rigid body disini adalah bahan yang digunakan untuk design lifeboat adalah sejenis FRP (Fiber Reinforce Plastics), yang mana bahan bahan dianggap kaku, tidak mengalami deformasi dan tegangan sehingga diasumsikan tidak akan pecah bila mengalami tumbukan dengan air.

- Kondisi perairan adalah still water (air tenang)
Kondisi perairan diasumsikan kondisi still water (air tenang), dengan tujuan untuk memperjelas presentasi ketika lifeboat bertumbukan dengan air dan akselerasi yang terjadi pada penumpang akibat tumbukan tersebut.

- Jenis material yang digunakan diasumsikan isotropis (memiliki perilaku kekuatan yang sama di segala arah). Hal ini dimaksudkan untuk mempersingkat waktu perhitungan dan analisa.

\section{Tujuan Penelitian}

Paper ini bertujuan untuk mengembangkan sebuah model simulasi yang berfungsi untuk memprediksi besarnya respon akselerasi FFL akibat tumbukan dengan permukaan air dengan mempertimbangkan parameter ketinggian lokasi peluncuran dan sudut Luncur dari rel (Skid) FFL dan distribusi muatan penumpang FFL.

\section{Kontribusi Penelitian}

Penelitian ini diharapkan mampu memberikan alternatif estimasi besarnya respon akselerasi FFL, sebagai dasar penentuan tingkat keselamatan pengguna FFL dengan menggunakan pendekatan pemodelan simulasi. Yang mana hal ini sangat diperlukan dalam tahap perancangan FFL. Beberapa kontribusi lain adalah sebagai berikut:

- Kemampuan memprediksi Launching Trajectory Behavior FFL

- Pengembangan aplikasi metode Abritary Lagrangian-Eularian (ALE) Coupling

- Implementasi teknik pemodelan simulasi dalam kajian keselamatan penumpang FFL

\section{TINJAUAN PUSTAKA Pengantar}

Sebuah sistem evakuasi Free Fall Lifeboat (FFL) didesain agar menjadi cepat dan handal. Pada saat penumpang menggunakannya, FFL dengan mudah meluncur di atas rel dari kapal atau bangunan lepas pantai sebelum jatuh bebas. Beberapa detik setelah terjadi tumbukan dengan air, sistem propulsi dapat dinyalakan dan lifeboat dapat segera menjauhi kapal atau bangunan yang sedang mengalami bencana. Berdasarkan perilaku ini, bagian yang perlu dicermati telah diidentifikasikan yang meliputi: tekanan pada lambung ketika seluruhnya terbenam di air (Fully Submerge), laju lifeboat setelah keluar dari air, beban akselerasi pada penumpang pada saat terjadi tumbukan terhadap air.

Pada tahun 2006, Norwegian Oil Industry Association (OLF) bersama dengan Norwegian Marine Technology Research Institute (MARINTEK) melaksanakan uji model yang ditujukan untuk mengetahui tingkat akselerasi pada penumpang ketika terjadi tumbukan. Beban akselerasi pada perairan 
bergelombang ditemukan dalam beberapa kasus memberikan hasil yang lebih besar dibandingkan dengan air tenang. Mereka juga menemukan bahwa hal ini dipengaruhi oleh beberapa parameter, khususnya bentuk lambung, distribusi massa, sudut datang gelombang (wave heading) relative terhadap lifeboat dan impact point pada permukaan gelombang.

Beberapa hasil eksperimen telah dipublikasi dalam hal ini. Arai et al. [2] mengkaji hal yag berhubungan dengan akselerasi, Simoes $\mathrm{Re}$ and Veitch [3] gerakan FFL setelah keluar dari air. Kajian teori tentang perilaku lifeboat pada saau masuk dan keluar dari air, berdasarkan Computational Fluid Dynamic sangatlah terbatas yang telah dipublikasikan. Pada kasus yang lain, khususnya yang berhubungan metode numerik dengan pemodelan simulasi dalam menganalisa respon akselerasi akibat beban tumbuk hanya ditemukan satu studi yang telah dipublikasikan. Frazer Nash Concultancy Limited mengunakan DYNA3D untuk memodelkan skenario tumbukan termasuk kinematika peluncuran, respon struktur lifeboat dan respon penumpang akibat tumbukan [4]. Penelitian ini akan melakukan hal yang serupa dengan pemodelan kinematika peluncuran yang telah dilakukan oleh Frazer and Nash, namun model simulasi yang akan dikembangkan dilengkapi dengan pemodelan accelerometer untuk mencatat besarnya respon akselerasi l.

\section{Teori Kinetika Peluncuran Lifeboat}

Kinetika peluncuran adalah perilaku keseluruhan lifeboat yang mendeskripsikan trajektori dan akselerasi. Untuk target ini lifeboat diperlakukan sebagai rigid body (dengan massa dan inertia yang tepat). Gaya yang diterapkan menggambarkan interaksi dengan rel peluncuran, gravitasi dan interaksi dengan air. Mekanisme dalam sistem peluncuran ini dibagi menjadi empat tahapan peluncuran, yaitu meluncur diatas rel, rotasi pada ujung, jatuh bebas, dan masuk ke dalam air.

\section{Tahap meluncur di atas rel}

Gaya-gaya yang bekerja pada tahap ini ditunjukkan pada Gambar 2. Persamaan gerak adalah sebagai berikut:

$$
\begin{aligned}
& M \cdot x^{\prime \prime}=F_{w X}+\left(F_{n 1}+F_{n 2}\right)(\cos \alpha-\mu \sin \alpha) \\
& M \cdot z^{\prime \prime}=F_{w Z}-M g+\left(F_{n 1}+F_{n 2}\right)(\sin \alpha+\mu \cos \alpha) \\
& I \cdot \theta^{\prime \prime}=0
\end{aligned}
$$

Yang mana,

$\mathrm{F}_{\mathrm{n} 1}=$ Gaya reaksi normal pada $\mathrm{B}_{\mathrm{xx}}$

$\mathrm{F}_{\mathrm{n} 2}=$ Gaya reaksi normal pada $\mathrm{B}_{\mathrm{x} 2}$

$\mathrm{F}_{\mathrm{wx}}=$ Gaya horizontal terhadap drag udara

$\mathrm{F}_{\mathrm{wz}} \quad=$ Gaya vertical terhadap drag udara

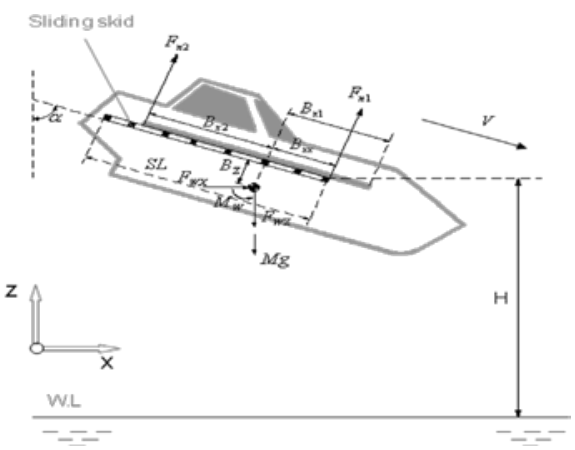

Gambar 2. Meluncur diatas rel

Berdasarkan persamaan diatas lifeboat mendapatkan energi kinetik dari akselerasi disepanjang sumbu lifeboat. Akselerasi lifeboat ini tergantung dari besarnya sudut luncur dari rel, koefisien gesek dari rel dan lifeboat. Kecepatan lifeboat pada ujung rel, tergantung dari akselerasi dan jarak yang ditempuh sepanjang rel.

\section{Tahap rotasi di ujung rel}

Tahapan rotasi terjadi karena center of gravity dari lifeboat telah melewati ujung rel. Momen putar dihasilkan karena adanya gaya gravitasi dan gaya reaksi pada ujung rel. Persamaan yang digunakan sama dengan persamaan pada tahap meluncur di rel. lihat gambar 2.2.

$M \cdot x^{\prime \prime}=F_{w x}+\left(F_{n 1}+F_{n 2}\right)(\cos \alpha-\mu \sin \alpha)$

$M \cdot z^{\prime \prime}=F_{\mathrm{wz}}-M g+\left(F_{n 1}+F_{n 2}\right)(\sin \alpha+\mu \cos \alpha)$

$I \cdot \theta^{\prime \prime}=0$

\section{Tahap rotasi di ujung rel}

Tahapan rotasi terjadi karena center of gravity dari lifeboat telah melewati ujung rel. Momen putar dihasilkan karena adanya gaya gravitasi dan gaya reaksi pada ujung rel. Persamaan yang digunakan sama dengan persamaan pada tahap meluncur di rel. lihat gambar 3.

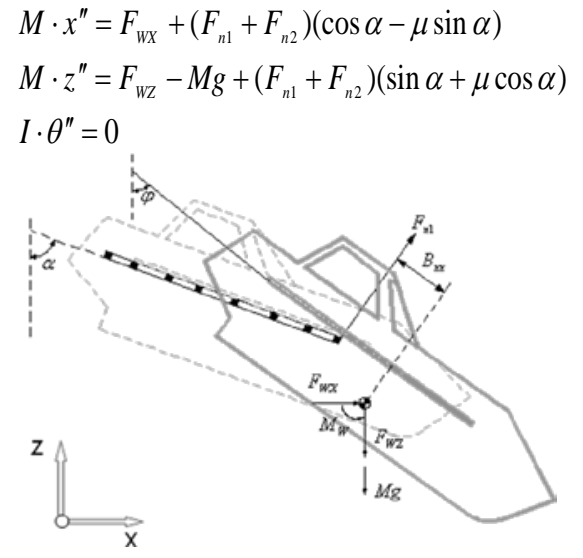

Gambar 3. Gerakan rotasi pada ujung rel 
Pada tahap ini, kinetika peluncuran tergantung dari massa, distribusi massa pada lifeboat, momen inersia lifeboat, koefisien gesek antara rel dengan lifeboat juga sudut luncur rel. kecepatan linier dan angular lifeboat pada akhir tahapan ini tergantung dari panjang lifeboat setelah center of gravity.

\section{Tahap jatuh bebas}

Pada saat lifeboat meninggalkan rel maka lifeboat berada dalam kondisi jatuh bebas. Gaya yang bekerja pada tahap ini hanyalah gravitasi, bila diambil asumsi pengaruh akibat angin diabaikan. Pada kondisi ini lifeboat masih terus berotasi dengan kecepatan sudut yang sama pada saat meninggalkan rel. Persamaan gerak yang digunakan adalah sebagai berikut:

$$
\begin{aligned}
& M \cdot x^{\prime \prime}=0 \\
& M \cdot z^{\prime \prime}=-M g \\
& I \cdot \theta^{\prime \prime}=0
\end{aligned}
$$

Sudut masuk ke dalam air (water entry angle) pada akhir tahap ini tergantung kecepatan angular dari tahapan rotasi dan tinggi jatuh bebas. Semakin besar tinggi jauh bebas semakin tajam sudut masuk kedalam air.

\section{Tahap masuk kedalam air}

Pada saat lifeboat masuk kedalam air, gayagaya yang bekerja terjadi akibat air dipindahkan oleh badan lifeboat. Pengabaian pengaruh tegangan permukaan, sumber-sumber penyebab gaya dapat diidentifikasikan sebagai pengaruh buoyancy dan drag.

\section{- $\quad$ Pengaruh buoyancy}

Ketika sebuah badan terbenam baik secara penuh ataupun sebagian, maka akan menerima tekanan. Bila tekanan tersebut secara uniform diterima oleh seluruh bagian panampang maka tidak terdapat gaya resultant terhadap objek. Namun bila besaran tekanan tersebut bervariasi (akibat kedalaman) maka terdapat gaya resultan netto yang diterima objek.

Yang mana,

$$
\mathrm{P}_{\text {buoy }}-\rho_{\text {water }} \mathrm{g} \mathrm{h}
$$

$\begin{array}{ll}\mathrm{P}_{\text {buoy }}= & \text { Tekanan akibat pengaruh } \\ \text { buoyancy } & \\ \rho_{\text {water }}= & \text { Densitas air } \\ \mathrm{g} \quad= & \text { percepatan gravitasi } \\ \mathrm{h} \quad \text { kedalaman terhadap } \\ \text { permukaan air } \\ \text { Gaya inilah yang biasa disebut gaya buoyancy. } \\ \text { Gaya buoyancy adalah jumlah netto dari } \\ \text { besarnya tekanan yang bekerja pada tiap-tiap } \\ \text { bagian lifeboat yang berada dalam kedalaman } \\ \text { yang berbeda-beda dibawah air. }\end{array}$

- $\quad$ Pengaruh drag

Besaran gaya drag sulit ditentukan karena gaya ini merepresentasikan mekanisme hilangnya energi yang tergantung dari beberapa faktor antara lain: bentuk, tekstur permukaan dan sebagainya.

Umumnya drag menyebabkan tiga pengaruh. Pertama, tekanan drag meningkat ketika air dipaksa untuk berubah arah akibat tubrukan dengan lifeboat, atau aliran air tidak parallel dengan permukaan. Kedua, energy hilang akibat gesekan antara aliran air dan permukaan lifeboat yang sejajar dengan aliran. Efek ini biasa dikenal sebagai drag profil. Ketiga, inersia air, merepresentasikan energi yang diperlukan untuk menggeser air ketika lifeboat masuk, penyebab gelombang. Pengaruh ini sangat sulit untuk dikuantifikasikan.

$\begin{array}{llll}\mathrm{F}_{\text {drag }} & = & \text { Gaya Drag } \\ \mathrm{C}_{\mathrm{D}} & = & \text { Koefisien drag } \\ \text { menggambarkan } & \text { efek netto dari semua drag } \\ \mathrm{V}_{\text {body }}= & \text { Kecepatan lifeboat } \\ \mathrm{V}_{\text {water }}= & \text { Kecepatan aliran air } \\ \rho_{\text {water }}= & \text { Densitas air } \\ \mathrm{A} & = & \text { Area badan lifeboat, }\end{array}$
normal terhadap aliran

\section{Kriteria Cidera (Injury Criteria) IMO pada FFL}

Selama peluncuran Free Fall Lifeboat (FFL), ada potensi terjadinya cidera pada penumpang. Potensi cidera ini disebabkan beban akselerasi yang diterima oleh penumpang ketika FFL menabrak permukaan air. Proses sertfikasi IMO pada sebuah desain FFL hakekatnya adalah sebuah evaluasi potensi terjadinya cidera.

Ketika membahas mengenai cidera, dan kriteria untuk diterimanya sebuah cidera, perlu diingat bahwa cidera adalah sebuah spectrum yang terbentang mulai dari cidera ringan hingga cidera fatal yang bias merenggut jiwa. Tidak ada definsi yang jelas tentang cidera yang biasa diterima ataupun ambang batas dari cidera. Namun pertimbangan utama ketika mengevaluasi cidera akibat impak dan percepatan adalah usaha untuk tetap menjaga tingkat kesadaran (preservation of consciousness). Lari dari keadaan bahaya pada sebuah kapal atau bangunan lepas pantai atau beberapa hal darurat lainnya, tergantung dari perawatan kesadaran (maintenance of consciousness). Seluruh escape system didesain dan diuji untuk meminimalisasi resiko cidera kepala. Bila kepala mengalami cidera kritis, permasalahan bagaimana cara melarikan diri bukanlah menjadi masalah yang berarti. 
Keadaan darurat di dunia maritime, mengevakuasi kapal atau bangunan lepas pantai hanyalah bagian dari proses bertahan hidup. Setelah memindahkan korban dari daerah bahaya, aksi-aksi diperlukan untuk memberdayakan awak agar bisa ditolong dengan selamat. Tugas-tugas tersebut meliputi: merawat luka dan cidera, mengumpulkan dan mendistribusikan air dan makanan, penyelamatan lingkungan dan mengirim catatan pencarian posisi bencana pada tim penyelamat. Tugas-tugas ini hanya bisa dilaksanakan bila penumpang lifeboat berada dalam keadaan sadar.

\section{Square root of the squares acceleration criteria}

Kriteria akselerasi SRSS didasarkan pada asumsi bahwa domain gaya akselerasi yang aman bagi tubuh manusia dapat didefinisikan dalam ellip soidal envelop. Combined Acceleration Reponse didefinisikan sebagai berikut:

$C A R=\sqrt{\left(\frac{a_{\bar{\xi}}}{A_{\bar{\xi}}}\right)^{2}+\left(\frac{a_{\bar{\eta}}}{A_{\bar{\eta}}}\right)^{2}+\left(\frac{a_{\bar{\zeta}}}{A_{\bar{\zeta}}}\right)^{2}}<1.0$

$A_{\bar{\eta}}, A_{\bar{\xi}}, A_{\bar{\zeta}}$ adalah nilai batas akselerasi yang direkomendasikan olah IMO berdasarkan tabel 1

Tabel 1. Allowable Acceleration untuk evaluasi

\begin{tabular}{cc}
\hline Coordinate axis & $\begin{array}{c}\text { Allowable } \\
\text { acceleration (A) }\end{array}$ \\
\hline (eyeballs in/out) & $15 g$ \\
(eyeballs left/right) & $7 g$ \\
(eyeballs up/down) & $7 g$ \\
\hline
\end{tabular}

\section{METODOLOGI}

Paper ini bertujuan untuk menawarkan suatu metode analisa peluncuran Free Fall Lifeboat (FFL) dengan mengembangkan model simulasi untuk evaluasi keselamatan penumpangnya. Adapun tahapan metode yang akan dilakukan adalah meliputi, pemodelan lifeboat dan fluida air, pemodelan contact dan coupling, running model beserta analisa dan terakhir akan diambil suatu kesimpulan.

Mengacu pada beberapa penelitian sebelumnya, khususnya mengenai studi perilaku peluncuran FFL. Fraser and Nash model, akan dijadikan dasar pengembangan model simulasi dalam paper ini. Datadata yang diperlukan pada awal tahapan pengembangan model adalah data dimensi dan desain lifeboat. Pada awal tahap metode ini ditentukan dimensi lifeboat yang akan dimodelkan.

\section{Pemodelan lifeboat dan Fluida Air}

Pemodelan lifeboat sebagai komponen elemen rigid body dilakukan dengan menggunakan bantuan software LS-PrePost Ver 2.4 setiap property dari komponen lifeboat didefinisikan sesuai dengan karakteristik mekanik material, yang mana dalam hal ini material yang digunakan adalah FRP (Fiber Reinforce Plastics). Pemodelan geometri dilakukan dengan mengacu pada gambar desain dari lifeboat, hal ini harus dilakukan dengan presisi mengingat bentuk geometri akan berpengaruh terhadap besarnya beban impak yang diterima oleh FFL. Setelah pemodelan lifeboat, kemudian pemodelan fluida air yang menggunakan elemen euler, untuk memodelkan perilaku air pada proses peluncuran ini.

\section{Pemodelan contact dan coupling}

Pada pengembangan model simulasi ini diperlukan pendefinisian contact dan coupling. Pendefinisian contact dilakukan untuk mendefinisikan fungsi contact antar elemen lagrangian. Hal ni diperlukan ketika akan memodelkan contact antara rel dengan lifeboat. Disisi lain diperlukan pendefinisian coupling untuk mendefinisikan coupling antara elemen lagrangian dengan elemen eulerian. Metode coupling yang akan digunakan dalam pemodelan simulasi ini adalah Simplified ALE Coupling dari LS-Dyna. Metode ini sangat handal dalam memodelkan kasus Fluid Structure Interaction karena dapat menghemat waktu komputasi. Namun Simplified ALE Coupling hanya dapat digunakan untuk fluida dengan single density, hal ini memungkinkan karena tidak ada perubahan densitas akibat perubahan tekanan yang terjadi karena beban impak. Asumsi ini diambil karena proses impak yang terjadi berada diperairan terbuka sehingga respon terhadap pressure berupa displacement air dan gelombang pada permukaan air.

\section{Running Model and Analisa}

Model simulasi yang dikembangkan akan dirunning berdasarkan beberapa skenario yang telah disyaratkan oleh IMO. Ketinggian jatuh bebas yang akan digunakan dalam model ini ditentukan sesuai dengan ketinggian pada saat lifeboat akan digunakan. Adapun variasi yang menjadi variable utama dalam hal ini adalah distribusi muatan :

- $\quad$ Skenario 1 : Full load condition

- $\quad$ Skenario 2 : 50\% load condition in Foreward

- $\quad$ Skenario 3 : 50\% load condition in Afterward

- $\quad$ Skenario 4 : empty condition 


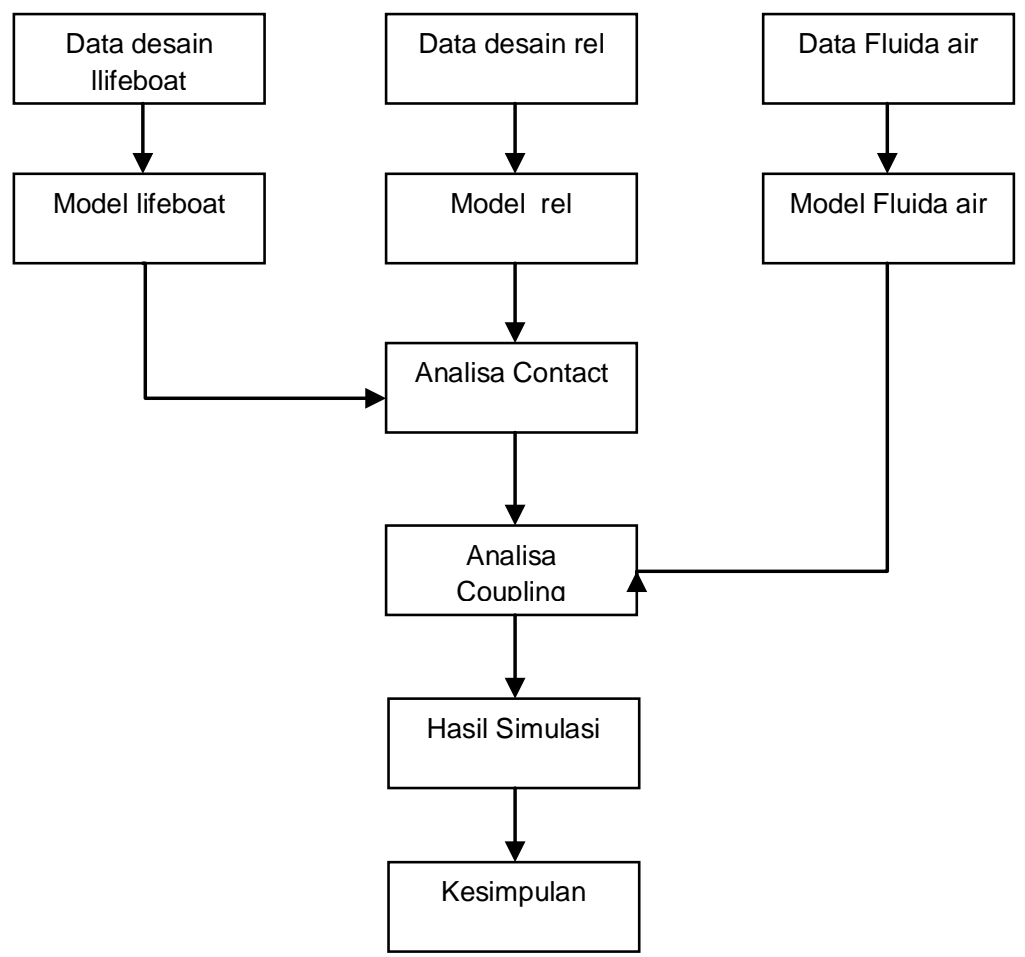

Gambar 4. Diagram Alir Penelitian

Pada tiap-tiap skenario, respon akselerasi dari model lifeboat kemudian ditabulasi dan dikaji dengan menggunakan kriteria penerimaan Combined Acceleration Response (CAR). Respon akselerasi terbesar dapat ditunjukkan dalam hasil analisis. Secara garis besar metodologi penelitian dapat dipresentasikan dalam flowchart seperti Gambar 4.

\section{HASIL PEMODELAN GEOMETRI LIFEBOAT}

Mengacu pada rumusan masalah dan metode penelitian ini, pemodelan geometri dibuat dengan menggunakan software LS-PrePost Ver 2.4 dapat dilihat pada gambar dibawah ini. Karena design lines plan sebuah lifeboat adalah hak patent produsen, maka dalam membuat bentuk geometri lifeboat, kita ambil asumsi prediksi geometri melalui gambar general arrangement yang didapatkan melalui internet. Dalam pemodelan geometri lambung, digunakan tipe elemen segiempat, hal ini dipilih sebab elemen segiempat memiliki karakteristik yang lebih akurat dibanding dengan elemen segitiga. Proses meshing pada geometri lifeboat diperlukan sejumlah 4805 elemen segiempat. Pada pemodelan fluida air digunakan elemen euler yang berbentuk solid. Pada pemodelan fluida air, ukuran lebar, panjang dan kedalaman disesuaikan dengan ukuran model lifeboat. Sejumlah 182000 elemen solid diperlukan untuk membuat fluida air.

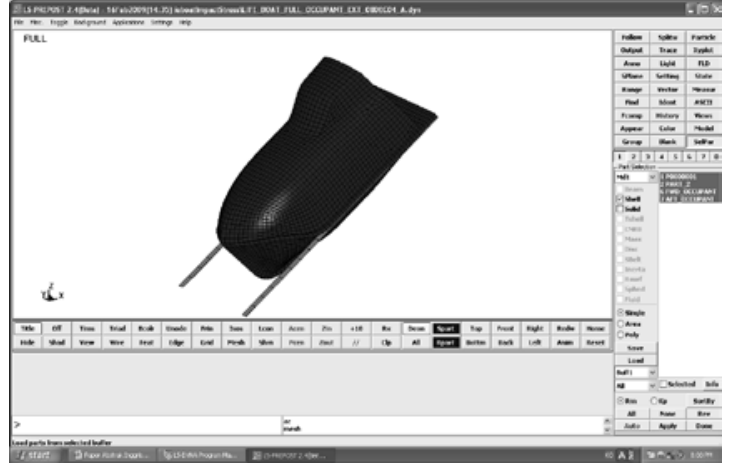

Gambar 5. Pemodelan lifeboat dengan software LSPrePost Ver 2.4

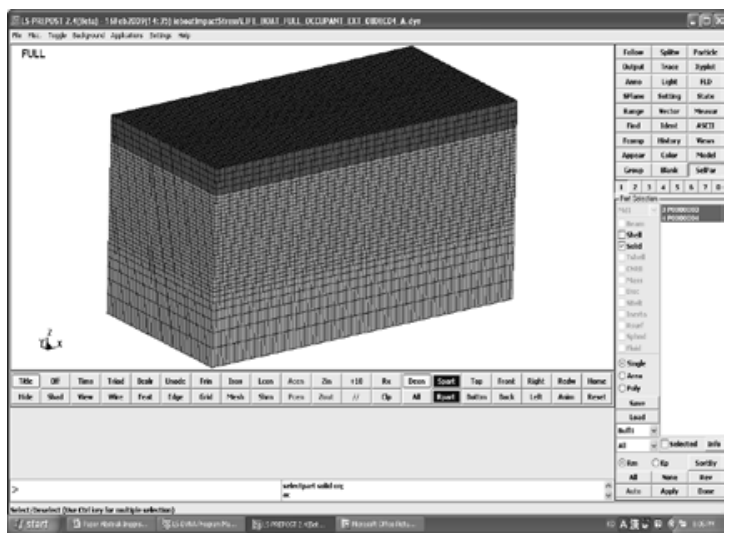

Gambar 6. Pemodelan fluida dengan software LSPrePost Ver 2.4 


\section{KESIMPULAN DAN SARAN}

Metode yang ditawarkan pada paper ini diharapkan mampu memberikan alternatif estimasi besarnya respon akselerasi FFL, sebagai dasar penentuan tingkat keselamatan pengguna FFL dengan menggunakan pendekatan pemodelan simulasi. Untuk mendapatkan model yang benar-benar akurat, validasi harus dilakukan dengan hasil eksperimen langsung pada peluncuran lifeboat. Diterimanya desain lifeboat harus memenuhi kriteria penerimaan Combined Acceleration Respon (CAR) dari IMO. Hasil penelitian pada paper ini masih dalam tahapan pemodelan lifeboat dan fluida. Hasil penelitian lanjutan dapat dijabarkan pada penelitian selanjutnya tentang free fall lifeboat dan dilengkapi hasil akselerasinya.

\section{DAFTAR PUSTAKA}

1. IMO, 2003. International life-saving appliances code

2. Arai, Kohndoker, and Inoue, 1995. Water entry simulaion of freefall lifeboat- $1^{\text {st }}$ report: Analysis of Motion and Acceleration. Journal of the Society of Naval Architects of Japan, vol. 178, pp. 193-201.

3. Simoes Re, A and Veitch, B., 2007. Experimental investigation of freefall lifeboat performance.Proc. ISOPE 2007, Lisbon.

4. Frazer-Nash Comsultancy Limited, Feasibility of Computer Simulation of the Launch of Freefall Lifeboat, Frazer-Nash Consultancy Limited, OTH 92 391, 1992

5. Sauder, T. Fouques, S, 2009, Theoritical study of the water entry of a body in waves. Application to Safety of Occupants in Freefall Lifeboat, Proc. International Conference on Ocean, Offshore and Arctic Engineering OMAE, Honolulu.

6. Nelson, J.K, Waugh, P J, Schweickhardt, A J, 1995.Injury Criteria of The IMO and The Hybrid III Dummy as Indicators of Injury Potential in Free Fall Lifeboat, Ocean Engineering, Vol 23, No. 5, pp. 385-401, Elsevier Science Ltd. 